\title{
Covid-19: Indian government vows to protect healthcare workers from violence amid rising cases
}

\author{
New Delhi, India
}

The Indian government has given an ordinance that makes violence against healthcare workers a non-bailable offence, punishable by up to seven years imprisonment, amid concerns that the covid-19 pandemic has stirred an upsurge of such targeted violence.

The ordinance-which amends India's Epidemic Diseases Act 1897 and seeks to protect doctors, nurses, and paramedic and community health workers from harassment or physical injury-signals the government's "zero tolerance" of violence against healthcare service personnel, officials said.

The move, amid India's rising covid-19 count, follows multiple incidents of violence and harassment of doctors and healthcare workers engaged in covid-19 care or contact tracing, and a demand from the Indian Medical Association (IMA) for protective legislation.

The IMA said, "Covid-19 has made us acutely aware of our helplessness against mindless abuse and violence. Stigma and social boycott are everywhere. Harassment by the administration is nothing but violence by the state."

Resident doctors in some government hospitals in Delhi who have raised concerns about shortages of personal protective equipment (PPE) have complained about hostile hospital administrations. In the central Indian town of Indore, healthcare workers engaged in contact tracing were attacked by a mob.

On 19 April a mob in the city of Chennai attacked an ambulance carrying the body of a neurosurgeon who had died after contracting covid-19. "If dignity is denied even in death, our patience and restraint lose their value," said the IMA, the country's largest body of doctors.

Doctors attribute the surge in violence against healthcare workers to a mix of ignorance and fear amplified by the pandemic. Pradeep Kumar, an orthopaedic surgeon in Chennai who had worked with the neurosurgeon who died, told The BMJ, "Attacks on doctors have been a long standing problem in this country, even before the pandemic. The government has, for now, amended only the epidemic act. What happens when the pandemic is resolved? We need strict, permanent, and strongly enforced legislation."

India's confirmed covid-19 count increased to 21353 , including 681 deaths, on 23 April. The health ministry said the country's multiple initiatives-early screening of international travellers, isolation of positive cases, contact tracing, home quarantine of contacts, and the nationwide lockdown that began on 25 March-have averted a rapid rise in cases.

Doctors have warned that dozens of healthcare workers appear to have contracted the virus after working without adequate PPE. The health ministry has said that the government has procured masks and other protective equipment and released them for distribution to hospitals across the country.

Harjit Bhatti, a geriatric medicine specialist in New Delhi and president of the Progressive Medicos and Scientists Forum, a non-government group of physicians, told The BMJ: "Shortages of PPE persist in some places, but many doctors fear harassment from administrations so don't want to speak out."

He cited an instance in which a government hospital administration in New Delhi terminated the services of a senior resident after he personally procured face shields and distributed them to staff in the hospital. The doctor was reinstated after an uproar on social media.

Bhatti added: "Many doctors don't want to talk about this-they would rather risk infection than jeopardise their careers." 